\title{
Development of Carbon Based NPK Slow Release Fertilizer using Biochar from Oil Palm Empty Fruits Bunch
}

\author{
S.D. Sumbogo Murti ${ }^{1}$, Arfiana ${ }^{1}$, E. R. Finalis ${ }^{1}$, I. Noor ${ }^{1}$, H. Suratno ${ }^{1}$, E. Rosyadi ${ }^{1}$, H. Saputra ${ }^{1}$, R. \\ $\mathrm{Noda}^{2}$ \\ ${ }^{1}$ Center for Technology Energy Resources and Chemical Industry, BPPT, South Tangerang, \\ Indonesia \\ ${ }^{2}$ Chemical and Environment Engineering, Gunma University, Japan
}

Received 15 November 2019; Accepted 26 November 2019

Available online 28 February 2020

\begin{abstract}
Biochar is a solid material produced by thermochemical conversion of biomass under oxygen-limited conditions. It has a wide surface and contains many pores so that it can be used as a material for making fertilizer. Biochar based slow release NPK fertilizer was formulated and developed to reduce nutrient leaching and greenhouse gas emissions. In this research, biochar which was a by-product of biomass gasification using oil palm empty fruit bunches was processed to make slow release biochar NPK fertilizer. Sources of Nitrogen (N) were derived from Urea, Phosphate (P) from Diamonium Phosphate (DAP) and Potassium (K) derived from Potassium Chloride $(\mathrm{KCl})$. Zeolite was added as a matrix to improve fertilizer characteristics. All materials were formulated to make slow release biochar NPK fertilizer used for red onion (Allium sepa) plant applications. Several micronutrients were also added including $\mathrm{Mg}\left(\mathrm{MgSO}_{4}\right.$ fertilizer) and $\mathrm{S}$ (ZA fertilizer) to support plant growth. The characterization of fertilizer products was carried out by using SEM, BET etc. to determine physical properties including surface area, pore volume, morphology and composition. Furthermore, biochar NPK fertilizer was applied to the red onion plant which was a high-value crop in Indonesia. The application of NPK biochar fertilizer on red onion plant showed its superiority compared to commercial NPK fertilizers. In addition, the use of Magnesium and Sulfur micronutrients could support the growth of red onion bulbs so that they produced more and bigger bulbs.
\end{abstract}

Keywords: biomass, gasification, oil palm empty fruit bunches, biochar, slow release fertilizer

\section{Introduction}

Biomass is considered carbon neutral because $\mathrm{CO}_{2}$ emissions emitted from biomass combustion can be compensated by carbon assimilation that occurs in the process of photosynthesis of biomass. Indonesia is one of the countries with huge biomass potential, especially oil palm biomass (Directorate General of Estate Crops, 2016). The thermochemical decomposition process can convert biomass into syngas, bio-oil and bio-char. Biochar is a solid material formed from the thermochemical decomposition of biomass. Biochar is environmentally friendly and can be used for a variety of applications such as for soil remediation, greenhouse gas reduction etc. Lehmann \& Joseph, 2009). The main component of biochar is Carbon (C), also contains Hydrogen $(\mathrm{H})$ and Oxygen $(\mathrm{O})$, in addition there is also Nitrogen (N) and Sulfur (S) in small amounts (Liu, Charrua, Weng, Yuan, \& Ding, 2015). The composition of char elements is very dependent on biomass raw materials and the conditions of the biochar manufacturing process (Duku, Gu, \& Hagan, 2011; Kambo \& Dutta, 2015; Ahmad et al., 2014). Biochar has a large specific surface area, porous structure, surface functional group, and high mineral content, so biochar is widely used as an adsorbent for water and air pollutants(Ahmad et al., 2014; Mohan, Sarswat, \& Ok, 2014), catalysts for removing tar or producing biodiesel (Shen, 2015; Konwar, Boro, \&

\footnotetext{
* Corresponding author

E-mail address: sd.sumbogo@bppt.go.id
} 
Deka, 2014) and as land amendments (Duku, Gu, \& Hagan, 2011; Lone, Najar, Ganie, Sofi, \& Tahir, 2015). Biochar can be produced by pyrolysis, gasification hydrothermal carbonization and other thermochemical technologies (Cha et al., 2016).

Research shows that the biochar from Empty Fruits Bunch (EFB) of palm oil contains high concentrations of potassium so that it can be used as a source of potassium for NPK fertilizer (Sari, Ishak, \& Bakar, 2014). In addition, the physical properties of biochar from EFB which have a porous structure with a large surface area, has the potential to be used as a matrix for slow release fertilizer (SRF) on a biochar basis (Rukmowati \& Arbiwati, 2017).

The purpose of this study is to utilize biochar from EFB as a matrix of slow release NPK fertilizer for slow release fertilizer applied to red onion plants. In addition, $\mathrm{Mg}\left(\mathrm{MgSO}_{4}\right)$ and $\mathrm{S}$ (ZA fertilizer) micro nutrients are added to NPK fertilizer to increase the growth of red onion plants and produce much bigger and larger tubers.

\section{Material and Methods}

\subsection{Material}

The materials used in the manufacture of carbon based NPK fertilizer (C-NPK) are diammonium phosphate (DAP) as a source of phosphate, Urea as a source of Nitrogen, EFB char and Potassium Chloride as a source of Potassium. Molasses are used as a binding agent, Zeolite as a matrix and several micro nutrients such as $\mathrm{Mg}$ from $\mathrm{MgSO}_{4}$ fertilizer and $\mathrm{S}$ from ZA fertilizer. The EFB Char used is a by-product of EFB gasification that was carried out at PUSPIPTEK Serpong Banten using local EFB. Zeolites were obtained from Sukabumi, West Java, Indonesia. While other materials are obtained from the local market.

\subsection{Methods}

The process of making carbon based NPK (C-NPK) refers to procedures performed by Arfiana (2019). Briefly, the procedure for making C-NPK fertilizer is as follows; this C-NPK formula is a special formula for red onion where this fertilizer contains $15 \%$ Nitrogen, $10 \%$ Phosphate and $11 \%$ Potassium, which was added with $\mathrm{Mg}$ and S micronutrients 3 and 5\% respectively. All materials are crushed and mixed evenly until homogeneous, then granulated. During the granulation process the binding agent was sprayed to strengthen the bonds between the ingredients in forming granules. To reduce water content, the granules was dried at $70{ }^{\circ} \mathrm{C}$ for 60 minutes in the oven.

\subsection{Characterization and Analysis}

The characterization of C-NPK fertilizer was carried out to determine the effect of the carbon element on the C-NPK fertilizer that had been made. Characteristic tests performed included elemental composition, surface area, pore volume, morphology and functional analysis. Characteristic testing was carried out using a Brunauer - Emmet - Teller (BET Test), Fourier-Transform Infrared Spectroscopy (FTIR) and Scanning Electron Microscope (SEM).

\section{Result and Discussion}

\subsection{NPK Fertilizer}

The carbon source for C-NPK comes from char which is a by-product of EFB gasification at $600{ }^{\circ} \mathrm{C}$ using gasification facilities at PTSEIK. NPK, non char NPK and C-NPK fertilizers in this activity are shown in Figure 1. Unlike the light brown NPK, C-NPK looks black, which indicates the presence of carbon / char in the fertilizer. 


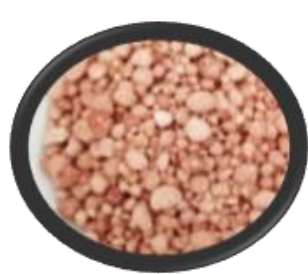

(a)

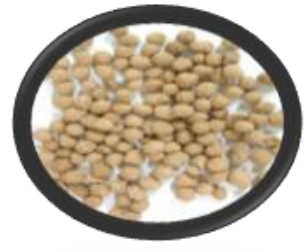

(b)

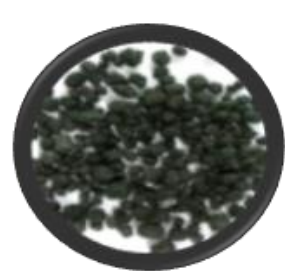

(c)

Figure 1. NPK Fertilizer (a) Commersial NPK, (b) non Char NPK and (c) C-NPK.

\subsection{Surface Area, Pore Volume and Pore Size of NPK Fertilizer}

Surface area, pore volume, and pore size of NPK fertilizer are measured using BET test according to ISO 9277-10 procedure. BET measurement results are shown in Table 1.

Table 1. BET measurement result.

\begin{tabular}{ccc}
\hline \multicolumn{1}{c}{ Properties } & Non char NPK & C-NPK \\
\hline Surface Area $\left(\mathrm{m}^{2} / \mathrm{g}\right)$ & 0.25530 & 24.449 \\
Pore Volume $(\mathrm{cc} / \mathrm{g})$ & 0.00625 & 0.1285 \\
Avg Pore Radius $(\AA)$ & 447.110 & 109.237 \\
\hline
\end{tabular}

Measurement of surface area, pore size of NPK fertilizer shows that there was a very large improvement in surface area and pore volume. The surface area of non-char NPK and C-NPK were 0.2530 and 24.449 $\mathrm{m}^{2} / \mathrm{g}$, respectively. Whereas for pore volume for non char NPK and C-NPK were 0.00625 and 0.1285 $\mathrm{cc} / \mathrm{g}$, respectively. The utilization of EFB char on the production of NPK fertilizer greatly increased the surface area and also pore volume. The surface area of C-NPK SRF increased almost 100 times greater than that of Non char NPK, while the pore volume rose about 20 times higher than that of non char NPK SRF fertilizer. The increasing of surface area and pore volume in C-NPK fertilizer might give positive effect on the fertilizer which allowed the fertilizer to bind more nutrients with more uniform distribution.

This shows that the use of EFB char as a NPK fertilizer matrix is very useful, both to increase the surface area and pore volume and can also be used as a source of potassium needed by plants.

\subsection{Morphology of NPK Fertilizer}

Morphological tests were conducted to determine the effect of char from EFB on the structure of NPK fertilizer, from which this test can determine the porosity of the sample. For this reason NPK fertilizer was observed and analyzed using SEM JEOL JSM-6510LA to see the surface morphology of the NPK fertilizer. The photograph from SEM is shown in Figure 2 where Figure $2 \mathrm{a}$ is the non char morphology of NPK while 2b is the morphology of C-NPK. Figure 2a shows surface morphology of non char NPK fertilizer where the pores are less clearly observable. While Figure $2 b$ clearly shows that C-NPK is porous and more porous than non char NPK. 


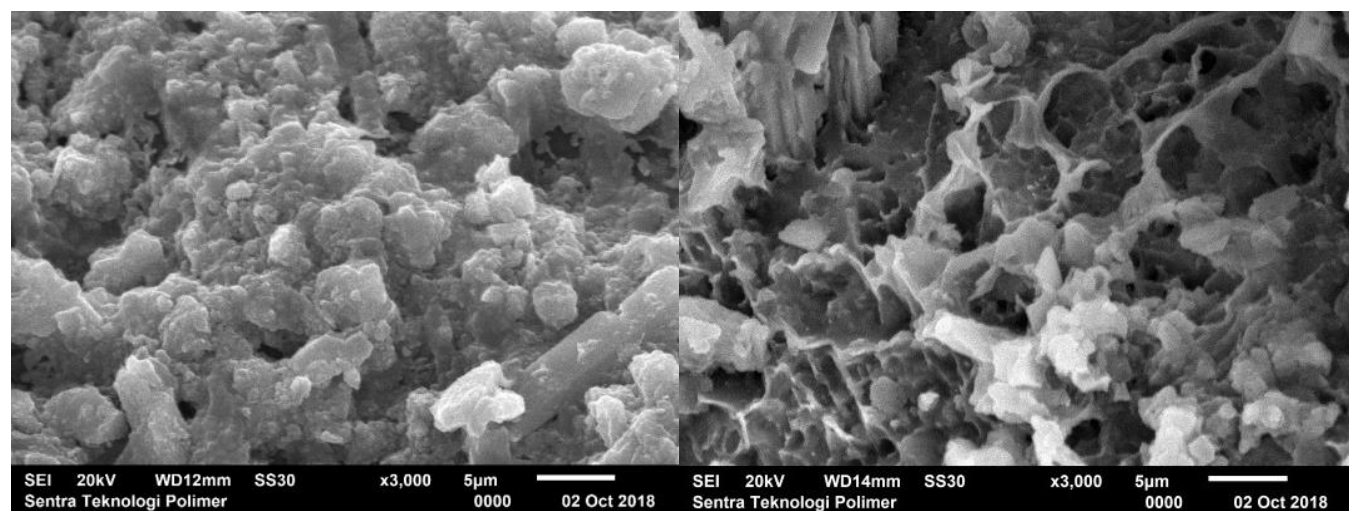

Figure 2. The morphology of (a) Non char NPK (b) C-NPK.

This porous structure occurs because of the evaporation or loss of volatile material during the char formation of char in the gasification reactor. This phenomenen is consistent with the report by Claoston et al. (2014), that in the process of gasification or pyrolysis at high temperatures volatile matter removal will occur so that it leaves a porous space. In addition, the two fertilizer structures do not show a smooth surface, which can be caused by the presence of micro-nutrient material attached to the fertilizer surface.

\subsection{Functional}

FTIR test was carried out to identify the effect of the utilization of EFB char on the NPK fertilizer functional group. In this test, the functional group of fertilizers was observed using the ASTM E573-13 method. The functional groups of non char NPK and C-NPK fertilizer from FTIR test results are shown in the Figure 3.

As shown in Figure 3, FTIR spectra for non char NPK and C-NPK fertilizers are similar, except for the peaks that appear in C-NPK fertilizers at $3075.74 \mathrm{~cm}^{-1}$ which are related to vibration stretching $\mathrm{C}-\mathrm{H}$, which is appropriate with Abdullah et al. (2011). Actually the absorption of saturated C-H stretches occurs below $3000 \mathrm{~cm}^{-1}$, so that any band structure observed above that value almost shows unsaturation $(\mathrm{C}=\mathrm{C}-\mathrm{H})$ and/or aromatic rings as as explained by Coates (2000). The number of wave numbers 3400 $3200 \mathrm{~cm}^{-1}$ on both fertilizers is the vibration stretching of O-H bonds (Claoston, Samsuri, Husni, \& Amran, 2014), including the hydroxyl functional group due to constant water content (Ooi, Ang, \& Yeoh, 2013) in fertilizer. While the wave numbers $2981 \mathrm{~cm}^{-1}$ and $2841 \mathrm{~cm}^{-1}$ are stretch vibrations for $\mathrm{C}-\mathrm{H}$ at the frequency of the saturated aliphatic (alkane/alkyl) group (Coates, 2000). Based on the FTIR test it can be said that the utilization of EFB char does not significantly change the functional group of NPK fertilizer.

(a)

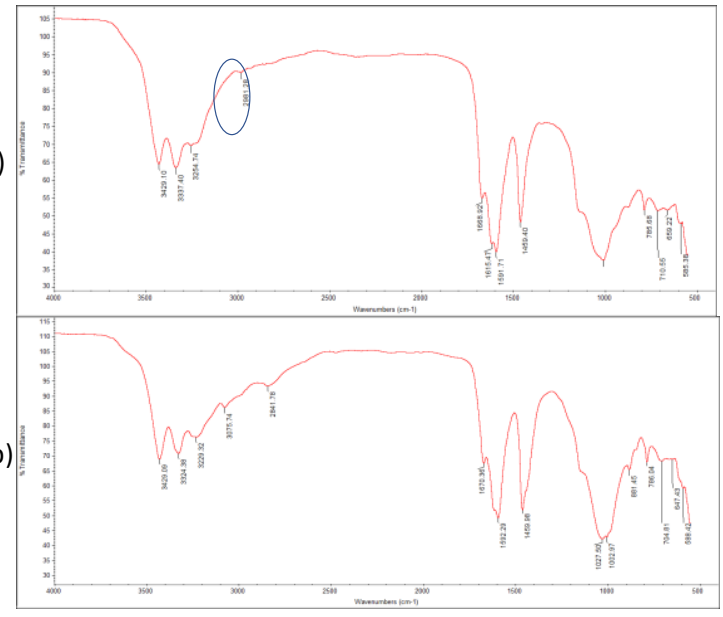

Figure 3. FTIR result of (a) Non char NPK (b) C-NPK. 


\subsection{Field Test Using NPK Fertilizer}

The field test using non char and C-NPK SRF fertilizer was conducted in Puspiptek for shallot/ red onion plant. The result of the field test was showed in Figure 4.

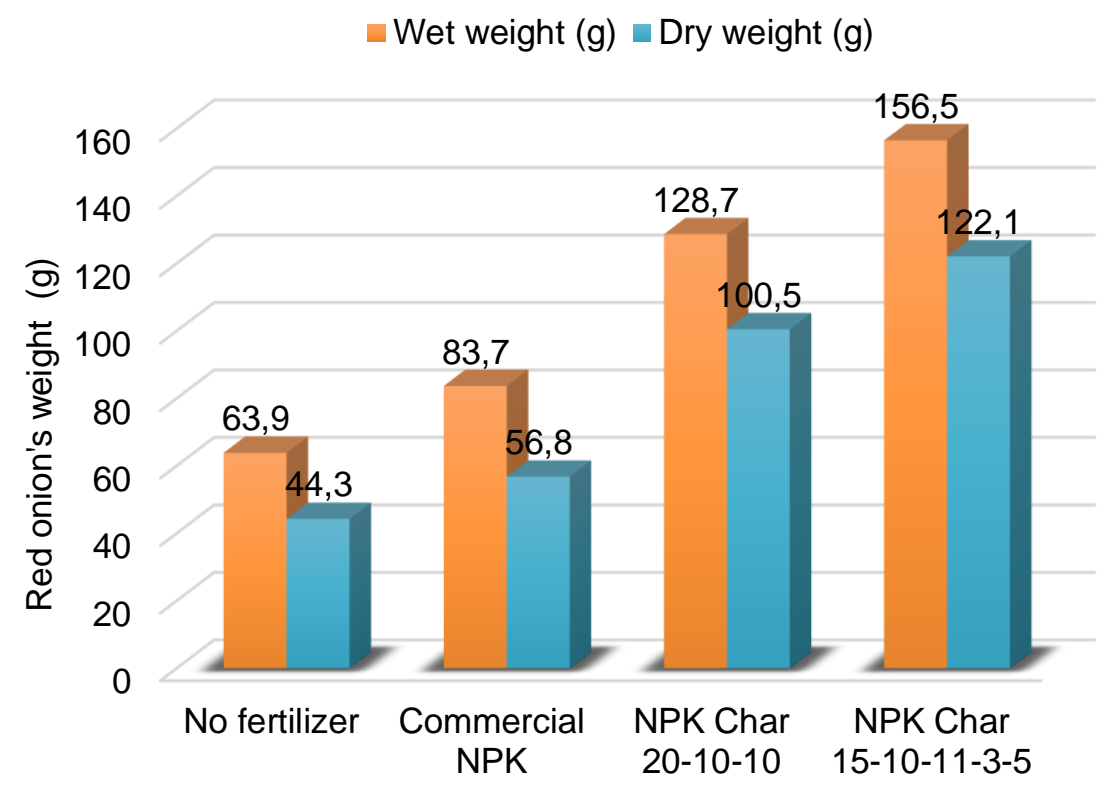

Figure 4. Weight of harvested onion.

As explained in Figure 4 above, utilization of carbon-based NPK SRF fertilizer shows advantages over commercial NPK. The use of C-NPK can increase the production of red onion by more than $50 \%$, from 83.7 to $128.7 \mathrm{~g}$. What's more, the addition of 3 and $5 \%$ micronutrient content in the form of $\mathrm{Mg}$ and $\mathrm{S}$ to C-NPK fertilizer with formula 15-10-11-3-5 turns out to give a higher production of red onion to 156.5 grams or an increase of $21 \%$. The use of Magnesium and Sulfur micronutrients can support the growth of red onion bulbs so that they can produce more and bigger bulbs. However testing in a larger area is needed to confirm these results.

\section{Conclusion}

Biochar empty fruit bunch has the potential to be used in the production of NPK fertilizer as a source of potassium. The utilization of biochar increased the pore volume, surface area and resulted the porous structure carbon-based NPK SRF compared to the Non char NPK SRF as well as the Commercial NPK. Compared to the commercial NPK, carbon-based NPK SRF significantly enhanced the productivity of red onion. The addition of micronutrient $\mathrm{Mg}$ and $\mathrm{S}$ gave the better harvest result over the Carbon-based NPK SRF 15-10-11.

\section{Acknowledgments}

The authors would like to thank to The Agency of Assessment and Application of Technology and Japan Government through the SATREPS Project (Science and Technology Research Partnership for Sustainable Development) for financial support. 


\section{References}

Abdullah, N., Sulaiman, F., Gerhauser, H. (2011). Characterization of Oil Palm Empty Fruit Bunches for Fuel Application, Journal of Physical Science. (Vol. 22 (1), pp. 1 -24).

Ahmad, M., Rajapaksha, A.U., Lim, J.E., Zhang, M., Bolan, N., Mohan, D., Vithanage, M., Lee, S.S., Ok, Y.S. (2014). Biochar as a sorbent for contaminant management in soil and water: a review, Chemosphere (Vol. 99, p. 19). doi: 10.1016/j.chemosphere.2013.10.071. Epub 2013 Nov 27.

Arfiana, Finalis, E.R., Fausiah, Noor, I., Destian, E.F., Nuswantoro, D.B.I., Murti, S.D.S., Saputra, H., Noda, R. (2019). Utilization of empty fruit bunch (EFB) char in the production of NPK slow release fertilizer (SRF). AIP Conference Proceeding 2019. doi.org/10.1063/1.5098226

Cha, J.S., Park, S.H., Jung, S.C., Ryu, C., Jeon, J.K., Shin, M.C., Park, Y.K. (2016). Production and utilization of biochar: A review. Journal of Industrial and Engineering Chemistry (Vol. 40 p. 1-15).

Claoston, N., Samsuri, A.W., Husni, M.H.A., Amran, M.S.M. (2014). Effect of Pyrolysis Temperature on the Physicochemical Properties of Empty Fruit Bunch and Rice Husk Biochars, Waste Management \& Research (Vol. 32 (4), pp. 331 - 339).

Coates, J. (2000). Intrepretation of Infrared Spectra, A Practical Approach, in Encyclopedia of Analytical Chemistry, edited by R. A. Meters. (John Wiley \& Sons Ltd, Chichester).

Directorate General of Estate Crops. (2016). The Crop Estate Statistics of Indonesia: 2015-2017 Palm Oil. Secretariats of Directorate General of Estate Crops

Duku, M.H., Gu, S., Hagan, E.B. (2011). Biochar production potential in Ghana: A review, Renew. Sustain Energ. (Rev. 15, p. 3539-3551).

Kambo, H.S., Dutta, A. (2015). A comparative review of biochar and hydrochar in terms of production, physico-chemical properties and applications Renew. Sust. Energ. (Rev. 45 p. 359).

Konwar, L.J., Boro, J., Deka, D. (2014). Review on latest developments in biodiesel production using carbon-based catalysts, Renew. Sust. Energ. (Rev. 29, p. 546).

Lehmann, J., Joseph, S. (2009). Biochar for Environmental Management: An Introduction, Biochar for Environmental Management Science and Technology, Earthscans. (p. 1).

Liu, N., Charrua, A.B., Weng, C.H., Yuan, X., Ding, F. (2015). Characterization of biochars derived from agriculture wastes and their adsorptive removal of atrazine from aqueous solution: A comparative study, Bioresour. Technol. (Vol. 198, p.55-62). doi: 10.1016/j.biortech.2015.08.129. Epub 2015 Sep 7.

Lone, A.H., Najar, G.R., Ganie, M.A., Sofi, J.A., Tahir, A.L.I. (2015). Biochar for Sustainable Soil Health: A Review of Prospects and Concerns, Pedosphere (Vol. 25, p. 639).

Mohan, D., Sarswat, A., Ok, Y.S. (2014). Organic and inorganic contaminants removal from water with biochar, a renewable, low cost and sustainable adsorbent-- a critical review, Bioresour. Technol. (Vol. 160 p.191). doi: 10.1016/j.biortech.2014.01.120. Epub 2014 Feb 8.

Ooi, C.H., Ang, C.L., Yeoh, F.Y. (2013). The Properties of Activated Carbon Fiber derived from Direct Activation from Oil Palm Empty Fruit Bunch Fiber, Advanced Materials Research (Vol. 686, pp. $109-117)$.

Rukmowati Brotodjojo, R.R., Arbiwati, D. (2017). Int'l Journal of Advances in Agricultural \& Environmental Engg. (Vol.4 pp. 89).

Sari, N.A., Ishak, C.F., Bakar, R.A. (2014). American Journal of Agricultural and Biological Science (Vol. 9 (3) pp.450 - 456).

Shen, Y. (2015). Chars as carbonaceous adsorbents/catalysts for tar elimination during biomass pyrolysis or gasification. Renew. Sust. Energ. (Rev. 43, p. 281). 